\title{
OPEN Visualization and quantification of dynamic intercellular coupling in human embryonic stem cells using single cell sonoporation
}

\begin{abstract}
Zhenzhen Fan ${ }^{1}$, Xufeng Xue ${ }^{2}$, Jianping Fu ${ }^{1,2}$ \& Cheri X. Deng ${ }^{1,2 \bowtie}$
Gap junctions (GJs), which are proteinaceous channels, couple adjacent cells by permitting direct exchange of intracellular molecules with low molecular weights. GJ intercellular communication (GJIC) plays a critical role in regulating behaviors of human embryonic stem cells (hESCs), affecting their proliferation and differentiation. Here we report a novel use of sonoporation that enables single cell intracellular dye loading and dynamic visualization/quantification of GJIC in hESC colonies. By applying a short ultrasound pulse to excite single microbubbles tethered to cell membranes, a transient pore on the cell membrane (sonoporation) is generated which allows intracellular loading of dye molecules and influx of $\mathrm{Ca}^{2+}$ into single hESCs. We employ live imaging for continuous visualization of intercellular dye transfer and $\mathrm{Ca}^{2+}$ diffusion in hESC colonies. We quantify cell-cell permeability based on dye diffusion using mass transport models. Our results reveal heterogeneous intercellular connectivity and a variety of spatiotemporal characteristics of intercellular $\mathrm{Ca}^{2+}$ waves in hESC colonies induced by sonoporation of single cells.
\end{abstract}

Cell-cell communication plays an essential role in controlling the organization, coordination, and development of multicellular organisms. While diverse mechanisms exist for the exchange of molecular information between cells, the proteinaceous channels between adjacent cells, known as gap junctions (GJs), provide a direct mechanism for the transfer of $\mathrm{Ca}^{2+}$ and other molecules of small molecular weight (MW) between neighboring cells ${ }^{1}$. Cell-cell metabolic and electrical coupling are mediated by such GJ intercellular communication (GJIC), which is critical for proper functions of multicellular organisms ${ }^{2}$. For example, loss of direct intercellular communication has been associated with cancer onset and progression ${ }^{3-5}$. GJs have also been found to play a critical role throughout the development of mammalian embryo ${ }^{6,7}$, as the coordinated development of multicellular embryonic tissues requires rapid and robust intercellular communications.

Human embryonic stem cells (hESCs), derived from the inner cell mass of pre-implementation human blastocysts, can differentiate into somatic cells associated with the three germ layers ${ }^{8}$. Isolation and in vitro culture of hESCs have opened new opportunities for studying basic stem cell biology and embryonic development ${ }^{9-16}$. Directed differentiation of hESCs generates specific cell types useful for regenerative medicine, disease modeling, and drug screening ${ }^{17}$. However, improved culture protocols for maintaining and controlled differentiation of hESCs are required for successful use of hESCs in these applications, and it has been recognized that cell-cell interaction during in vitro culture of hESCs remains an intriguing yet incompletely understood feature that emerges on a cell colony scale to mediate important hESC behaviors including pluripotency ${ }^{18,19}$ and community behaviors $^{20,21}$.

By allowing chemical signals ${ }^{19,22}$ and even mechanical effects to operate over multicellular distances, cell-cell communication enables hESCs to sense the presence of each other ${ }^{23}$ and coordinate their differentiation and function ${ }^{9,10,22,24}$. Not surprisingly, functional GJIC has been identified as a common feature of hESC colonies maintained under various culture conditions ${ }^{25,26}$. Since cell-cell communication affects hESC survival and differentiation, improved understanding of GJIC may help identify factors that promote efficient culture conditions of hESCs ${ }^{27}$.

Common techniques for assaying GJIC and its pathophysiological alternations ${ }^{28}$ include scrape loading/dye transfer (SL/DT), microinjection of fluorescent tracers, and paired electrophysiological recordings. In the SL/DT assay $^{28,29}$, mechanically scraping a cell monolayer disrupts the membrane of a large number of cells and allows 
small fluorescent dye molecules to enter the cytoplasm of live cells through functional GJ adjacent to disrupted cells. After removal of extracellular dye molecules in culture medium, GJIC is studied by examining spatial extent of dye transfer in the remaining live cells using fluorescent microscopy. The SL/DT assay allows assessment of average features of GJIC in a cell monolayer; however, evaluation of GJIC at the single cell level and the dynamic process of cell-cell communication is not feasible ${ }^{28}$. Microinjection of fluorescent tracer into cells ${ }^{30,31}$ offers single cell resolution for assessing GJIC; however, this method is low-throughput and labor intensive, typically requiring manual handling of individual cells. Similarly, paired electrophysiological recordings ${ }^{32,33}$, even though offering a superior temporal resolution, are limited to studying GJIC between a pair of cells. Electroporation, which uses electric pulses to disrupt cell membrane, can load dye molecules into a large number of cells ${ }^{34}$; but suitable electrodes and protocols are needed for single cell operations and minimizing cell detachment/death.

To overcome these limitations, we employed in this study single cell sonoporation as a new method for controlled dye loading and dynamic visualization of cell-cell coupling in hESC colonies. Established as imaging contrast agents for diagnostic ultrasound imaging ${ }^{35}$, microbubbles with stabilizing lipid or polymer shells (radius 1-3 $\mu \mathrm{m}$ ) are biocompatible and have also been exploited for non-viral intracellular drug/gene delivery applications ${ }^{35-38}$. When subjected to ultrasound excitation ${ }^{35,39,40}$, microbubbles expand/contract or even collapse, generating localized mechanical impact on cells to induce transient poration of cell membrane (sonoporation $)^{38,41,42}$. In particular, we have shown that single cell sonoporation ${ }^{38,42}$ mediated by acoustic cavitation of individual membrane-anchored microbubbles ${ }^{41,43}$ generated nanoscale, reparable pores on the targeted cells to allow controlled intracellular delivery of membrane impermeable molecules without affecting cell viability.

While sonoporation has been studied extensively for intracellular drug and gene delivery, in this study, we report a novel use of single cell sonoporation for assaying cell-cell communication in hESCs. Sonoporation is used to load fluorescent molecules into single cells and subsequent dynamic molecular coupling between the sonoporated cells and adjacent daughter cells was measured to assess GJIC at the single cell level. In addition, we report the use of single cell sonoporation for the initiation of intercellular $\mathrm{Ca}^{2+}$ waves from single cells to study their characteristics in hESC colonies. Conventional methods use endogenous signals or external chemical stimulants such as ATP ${ }^{44}$ to initiate $\left[\mathrm{Ca}^{2+}\right]_{\mathrm{i}}$ changes $^{45}$. However, global application of ATP or other chemical agents to cell culture medium was generally without spatial specification, making it difficult to investigate changes in $\left[\mathrm{Ca}^{2+}\right]_{i}$ that propagate from cell to cell in the form of intercellular $\mathrm{Ca}^{2+}$ waves. In contrast, in this study, we show that single cell sonoporation enables a bolus influx of $\mathrm{Ca}^{2+}$ into single cells, from which intercellular $\mathrm{Ca}^{2+}$ waves are initiated and detected with high spatiotemporal resolution ${ }^{36,46,47}$.

\section{Materials and methods}

Cell culture. Human embryonic stem cell line H9 (WA09, WiCell; NIH registration number: 0062) was cultured in a standard culture system using mTeSR1 medium (Stemcell Technologies) and lactate dehydrogenaseelevating virus (LDEV)-free human embryonic stem cell qualified reduced growth factor basement membrane matrix Geltrex (Thermo Fisher Scientific) per manufacturer instruction. The cell line was test negative for mycoplasma contamination (LookOut Mycoplasma PCR Detection Kit, Sigma-Aldrich). hESCs were seeded as single cells on glass bottom dishes (MatTek Corporation) coated with $1 \%(\mathrm{v} / \mathrm{v})$ Geltrex at a density of 20,000 cells $\mathrm{cm}^{-1}$ with ROCK inhibitor Y27632 (10 $\mu \mathrm{M}$; Tocris). $24 \mathrm{~h}$ after cell seeding, cell culture medium was replaced with fresh mTeSR1 medium without Y27632. Sonoporation experiments were conducted one day after cell seeding (day 1). For other experiments, hESCs were cultured in mTeSR1 medium up to day 8, without losing pluripotency. Culture medium was replenished daily.

Targeted microbubbles. In order to achieve stable spatial position of microbubbles on the cell surface to generate controlled single cell sonoproation, we functionalized microbubbles with Arg-Gly-Asp (RGD) peptides to attach to cells via RGD-integrin binding. Targestar-SA (Targeson) microbubbles $\left(1 \times 10^{9}\right.$ bubbles $\left./ \mathrm{ml}\right)$ were conjugated at room temperature to biotinylated Arg-Gly-Asp (RGD) peptides (Peptides International; $0.01 \mathrm{mg} /$ $\mathrm{ml}$ ) at a volume ratio of 10:1 for $20 \mathrm{~min}$. To conjugate RGD-microbubbles onto the cell surface, the culture medium in the cell culture dish was removed, followed immediately by addition of $50 \mu \mathrm{l}$ of RGD-microbubble solution. Then the cell culture dish was flipped upside down for $10 \mathrm{~min}$ to allow the microbubbles to be attached the cells via RGD-integrin binding. This microbubble concentration was adjusted to achieve a nominal ratio of 1 bubble per 10-20 cells in a hESC colony. The dish was flipped back and gentle washing was performed to remove unbound microbubbles.

Ultrasound application and single cell sonoporation using targeted microbubbles. As described previously ${ }^{37,38,40}$, sonoporation of hESCs was generated after conjugation of microbubbles to the cells. During experiment, the glass bottom dish with adherent hESCs was placed on the stage of an inverted microscope (Nikon Eclipse Ti-U). A single element planar transducer with central frequency of $1.25 \mathrm{MHz}$ (Advanced Devices, Wakefield, MA, USA; $6 \mathrm{~dB}$ beam width of $3.54 \mathrm{~mm}$, Rayleigh distance of $9 \mathrm{~mm}$ ) was positioned at $45^{\circ}$ relative to the horizontal direction, with its active surface submerged in the medium, aiming at the cells. The transducer was driven by a waveform generator (Agilent Technologies 33250A) and a $75 \mathrm{~W}$ power amplifier (Amplifier Research 75A250). Before each experiment, a small mental wire was used to align the acoustic field and optical field, and position the transducer $9 \mathrm{~mm}$ away from the cells on the dish bottom. A single pulse containing 10 sinusoidal cycles (total duration $\sim 8 \mu \mathrm{s}$ ), with peak acoustic pressure of $0.4 \mathrm{MPa}$, was applied to generate sonoporation of hESCs in this study.

Calibration of the ultrasound transducer was performed in free field using a $40 \mu \mathrm{m}$ calibrated needle hydrophone (HPM04/1, Precision Acoustics).

Cell viability was determined using Calcein-AM assay (Thermo Fisher) performed after sonoporation. 
Calcium imaging and characterization of intra-and inter-cellular calcium waves. The fluorescent microscopy imaging system used in this study has been described in detail in our previous work ${ }^{36,46,47}$. Briefly, $\mathrm{Ca}^{2+}$ indicator fura-2AM was used for monitoring intracellular free $\mathrm{Ca}^{2+}$ concentration in hESCs in this study. To load the dye, cells were incubated for $60 \mathrm{~min}$ in the incubator in complete cell culture medium containing $10 \mu \mathrm{M}$ fura-2 AM (Invitrogen, ThermoFisher) and $0.05 \% \mathrm{v} / \mathrm{v}$ of $10 \% \mathrm{w} / \mathrm{v}$ Pluronic F- 127 (Invitrogen, Carsbad, CA, USA). After incubation, excess dye was removed by gentle washing. The cell-seeded dish was placed on a $37^{\circ} \mathrm{C}$ heating stage on an inverted microscope (Eclipse Ti-U; Nikon, Melville, NY, USA). Real-time fluorescence imaging was performed using a monochromator (DeltaRAM X; PTI, Birmingham, NJ, USA) with $5 \mathrm{~nm}$ bandpass to repeatedly filter light from a $75 \mathrm{~W}$ xenon lamp at the various wavelengths. The exposure for each channel $(340 \mathrm{~nm}, 380 \mathrm{~nm}$, and $538 \mathrm{~nm})$ was set at $1 \mathrm{~ms}$. The excitation light was directed through a $20 \times$ Super Fluor objective (MRF00200; Nikon, Melville, NY, USA; NA 0.75) to the specimen and the light emitted from the cells was passed through a polychroic filter (73000v2; Chroma, Rockingham, VT, USA) with passbands in the green and red. The resulting series of 16-bit photomicrographs were acquired using a cooled CCD camera (Photometrics Cool Snap HQ, Tucson, AZ, USA) at $512 \times 512$ resolution. We used Easy Ratio Pro (PTI, Birmingham, NJ, USA) and Image J 1.42 (The National Institutes of Health, Bethesda, MD, USA) for image acquisition and analysis.

The emitted fluorescence intensities at $510 \mathrm{~nm}$ from fura- 2 in the cells with excitation at two different wavelength $(340 \mathrm{~nm}$ and $380 \mathrm{~nm}$ ) were continuously recorded with recording interval of $3.45 \mathrm{~ms}$ for two channels, and $5.17 \mathrm{~ms}$ for three channels. Total recording time was $6 \mathrm{~min}$ ( $1 \mathrm{~min}$ before and $5 \mathrm{~min}$ post ultrasound application). The ratio of the emitted intensities from the cells, which is proportional to the intracellular free calcium concentration, was obtained from experimental measurements. Post-processing was performed to generate ratiometric pseudocolor calcium images using a custom Matlab program, where the ratio of background corrected fluorescence intensities of $340 \mathrm{~nm}$ to $380 \mathrm{~nm}$ was used to encode the hue, while the intensity from $340 \mathrm{~nm}$ was used to modulate the display intensity. The intra- and inter-cellular calcium wave speed was quantified from the sequence of ratiometric images recorded during experiments.

Fluorescent imaging and quantification of cell-cell dye transfer and GJ permeability. Propidium iodide (PI, $668 \mathrm{Da}$ ) (Sigma Aldrich) was used as an indicator to visualize the GJIC in hESCs in this study after single cell dye loading using sonoporation ${ }^{38}$. PI is a cell impermeable, nucleic acid intercalating agent, thus only fluoresces (excitation at $538 \mathrm{~nm}$, emission at $610 \mathrm{~nm}$ ) after entering the cells where nucleic acids are present.

Before experiments for sonoporation, $100 \mu \mathrm{M}$ PI was added to the culture medium in the cell-seeded dish. Real time fluorescence microscopy was used to record videos of PI fluorescence inside cells after reversible sonoporation, which generated transient membrane disruption allowing loading of PI into single cells followed by subsequent dye transfer into neighboring cells ${ }^{46}$.

Estimation of cell-cell permeability using a semi-infinite medium diffusion model. The transient membrane pores generated by sonoporation permitted intracellular uptake of a fixed amount of PI in to single cells targeted by microbubbles. After loading of PI by sonoporation into the sonoporated cell, intracellular diffusion of PI within the sonoporated cell resulted in rapid spread of the molecules in the sonoporated (parent) cell. We assumed that the amount of PI within the parent cell reached a constant after the sonopration pore resealed. The subsequent cell-cell transport occurred through the region of contact between the two cells. Thus transfer of PI from a sonoporated cell to neighboring (recipient or daughter) cells and diffusion in the recipient cells may be effectively modeled as an $1 \mathrm{D}$ semi-infinite medium diffusion problem if the observation time is short for a given spatial dimension ${ }^{48}$. Specifically, semi-infinite medium assumption is valid if

$$
\eta=\frac{x}{\sqrt{4 D t}} \geq 3
$$

where $x$ is the spatial distance, $D$ the diffusion coefficient, and $t$ the time. For a typical diffusion coefficient of small molecules $7 \times 10^{-9} \mathrm{~cm}^{2} / \mathrm{s}$ and spatial length of $35 \mu \mathrm{m}$ and observation time of $50 \mathrm{~s}, \eta \approx 3$. Therefore under the condition of $\eta>3$, or $t>50 \mathrm{~s}$ after sonoporation, we consider PI diffusion from a sonoporated cell (PI concentration was assumed in the sonoporated cell as constant $\mathrm{C}_{1}$ due to rapid intracellular diffusion after dye loading) to a neighboring recipient cell with PI concentration of $\mathrm{C}_{2}(\mathrm{x}, \mathrm{t})$ as a $1 \mathrm{D}$ semi-infinite medium diffusion problem with the following equation of diffusion and initial condition,

$$
\begin{gathered}
\frac{\partial C_{2}}{\partial t}=D \frac{\partial^{2} C_{2}}{\partial x^{2}}, \\
C_{2}=0, x>0, t=0 .
\end{gathered}
$$

In addition, the rate of PI transport at the interface of the two cells $(x=0)$ is proportional to the concentration difference between the sonoporated cell and recipient cell,

$$
-D \frac{\partial C_{2}}{\partial x}=k\left(C_{1}-C_{2}\right), x=0,
$$

where $k$ is the permeability of the cell-cell barrier, which is the GJ permeability for molecular exchange between the adjacent cells.

We perform Laplace transform on Eq. (2) and considering the initial condition in Eq. (3), we obtain 


$$
D \frac{\partial^{2} \overline{C_{2}}}{\partial x^{2}}=p \overline{C_{2}}
$$

where $\overline{C_{2}}$ is the Laplace transform of $C_{2}(x, t)$. The boundary condition, Eq. (3), becomes

$$
-D \frac{\partial \overline{C_{2}}}{\partial x}=\frac{k C_{1}}{p}-k \overline{C_{2}}, x=0 .
$$

Solving Eq. (5) while considering Eq. (6), we obtain

$$
\frac{\overline{C_{2}}}{C_{1}}=\frac{h}{p(q+h)} e^{-q x}
$$

where $h=k / D$ and $q=\sqrt{p / D}$. Performing inverse Laplace transform, we obtain the PI concentration in the recipient cell as a function of time and location ${ }^{49}$

$$
\frac{C_{2}(x, t)}{C_{1}}=\operatorname{erfc}\left(\frac{x}{2 \sqrt{D t}}\right)-\exp \left(\frac{k}{D} x+\frac{k^{2} t}{D}\right) \times \operatorname{erfc}\left(\frac{x}{2 \sqrt{D t}}+k \sqrt{\frac{t}{D}}\right),
$$

Equation (8) is then used to estimate cell-cell permeability (or GJ permeability) $k$ and diffusion coefficient $D$ based on experimentally measured PI fluorescence intensity in a recipient cell. We determined a straight line inside the recipient cell perpendicular to the GJ plane to indicate spatial locations from the cell barrier. Along this line, PI fluorescence intensity values were extracted from recorded images at different time point, and fit to Eq. (8). Since the cell nucleus has high concentration of nucleic acids, which results in much higher PI fluorescence intensity in the nucleus than that in the cytosol, we excluded the nuclear PI data in model fitting and only used the PI data in the cytosol.

Estimation of cell-cell permeability using a quasi-steady state diffusion model. We also use a quasi-steady state diffusion model in this study for estimation of cell-cell permeability. In this model, we consider the average concentration of PI in a cell as a function of time without considering spatial variation, thus making the model a lumped parameter or compartmental model. We also regard the GJ as a thin, plane barrier separating two cells. Due to the small scale of the thin barrier compared to the volume of the cells, changes in PI concentration in a sonoporated cell, $\mathrm{C}_{1}(\mathrm{t})$, and in a recipient cell, $\mathrm{C}_{2}(\mathrm{t})$, are much slower than diffusion across the thin GJ plane. Thus molecule diffusion through the thin GJ barrier from a sonoporated cell to a neighboring recipient cell can be considered as a quasi-steady-state diffusion problem with the boundary conditions being the constant PI concentration in the two adjacent cells ${ }^{48}$. The diffusion equation within the thin barrier is thus

$$
\frac{\partial C_{m}}{\partial t} \approx 0 \approx D_{m} \frac{d^{2} C_{m}}{d y^{2}}
$$

where $D_{m}$ is the diffusion coefficient of PI within the GJ barrier, and $y$ is the spatial location within the barrier. Equation (9) has a solution

$$
C_{m}(y)=\Phi C_{1}-\Phi\left(C_{1}-C_{2}\right) \frac{y}{L}
$$

where $\Phi$ is the partition coefficient, $L$ the thickness of the GJ barrier, $y$ the spatial location within the membrane. The flux of PI across the barrier is obtained as

$$
J=-D_{m} \frac{d C_{m}}{d x}=\frac{D_{m} \Phi}{L}\left(C_{1}-C_{2}\right)=k\left(C_{1}-C_{2}\right),
$$

where $k=\frac{D_{m} \Phi}{L}$ is the permeability of the GJ barrier between two cells.

To find the concentration in the recipient cell $C_{2}$, we consider mass balance in the cell.

$[$ Volume $\times$ rate of increase of PI in cell 2] $]=[$ Area $\times$ influx of PI into cell 2 across the GJ from cell 1$]$ which can be expressed mathematically as,

$$
V_{2} \frac{d C_{2}}{d t}=J A_{m}=k A_{m}\left(C_{1}-C_{2}\right)
$$

where $V_{2}$ is the volume of recipient cell 2, $A_{m}$ is the area of GJ through which cell-cell transport occurs between the two cells.

Since a fixed amount of PI was loaded into a cell by sonoporation, concentration in the sonoporated cell, $C_{1}$, can be regarded as constant after the initial increase. Generally, $C_{1} \gg C_{2}$ and $C_{2}(t=0)=0$, thus solution for Eq. (12) is obtained

$$
\ln \left(C_{1}-C_{2}\right)=-\frac{k A_{m}}{V_{2}} t+\ln C_{1}
$$

or, 
A

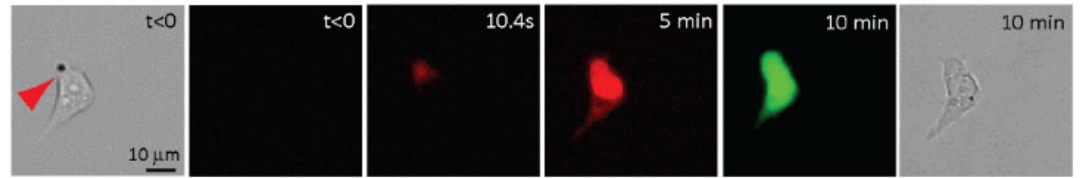

B
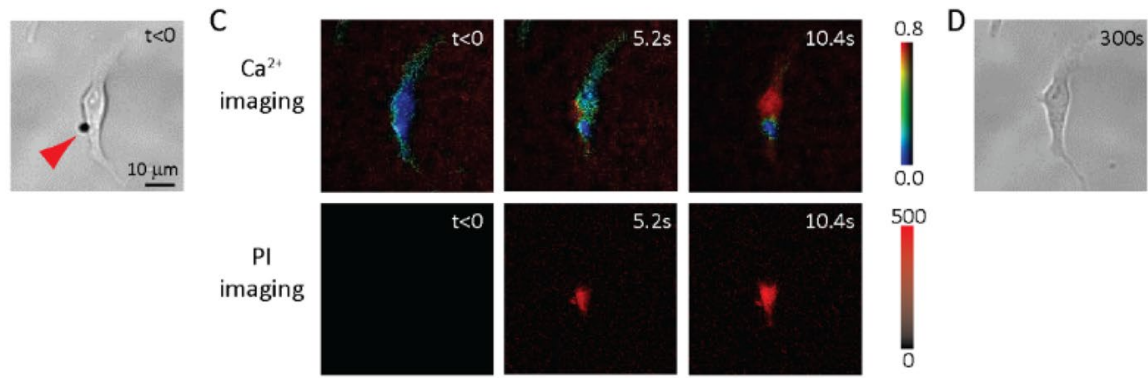

Figure 1. Microbubble mediated sonoporation allows intracellular uptake of propidium iodide (PI) and influx of $\mathrm{Ca}^{2+}$ in human embryonic stem cells (hESCs). (A) Sonoporation of a single hESC with an attached microbubble (arrow in the first bright field image before application of ultrasound pulse $t<0$ ) resulted in intracellular uptake of PI (red fluorescent signal) into the cell from the site of sonoporation. Calcein staining (green) confirmed cell viability after sonoporation $(\mathrm{t}=10 \mathrm{~min})$. (B) A hESC with an attached microbubble before sonoporation. (C) Simultaneous fluorescence imaging of intracellular $\mathrm{Ca}^{2+}$ and PI showing molecular entry after sonoporation. (D) The cell in (B) after sonoporation. Ultrasound pulse duration $8 \mu \mathrm{s}$, acoustic pressure 0.4 MPa.

$$
\frac{C_{2}(t)}{C_{1}}=1-\exp \left(-\frac{k A_{m}}{V_{2}} t\right)
$$

We use the PI fluorescence intensity from cell 1 (donor cell) and cell 2 (recipient cell) extracted from experimental recordings to fit Eq. (14) to estimate GJ permeability $k$. To meet the condition for the model, only data after a time period when $C_{1}$ reaches constant were used in model fitting. Cell volume was estimated by the product of measured cell area (from images) and a height of $5 \mu \mathrm{m}$. The area representing functional GJ was estimated from lateral length of connection between cells from images and a cell height of $5 \mu \mathrm{m}$.

\section{Results}

Sonoporation enabled single cell dye loading and dynamic visualization of GJIC in hESCs. Microbubbles functionalized with RGD were first stably attached to the surface of adherent hESCs via RGD-integrin binding (Fig. 1A,B). A short ultrasound pulse (duration $8 \mu \mathrm{s}$, acoustic pressure $0.4 \mathrm{MPa}$ ) was applied to induce single cell sonoporation ${ }^{38}$ by acoustic cavitation of the attached microbubbles (radius $1-2 \mu \mathrm{m}$ ) (Fig. 1A,B). Sonoporation generated transient pores on the cell membrane ${ }^{38,41,43}$, resulting in intracellular uptake of propidium iodide (PI) molecules without affecting cell viability, as assessed by calcein-AM assay (Thermo Fisher) performed $10 \mathrm{~min}$ after sonoporation (Fig. 1A), similar to what we reported before due to a transient (lasting for $\sim 5 \mathrm{~s}$ ), small $(5-20 \mathrm{~nm})$ pore on the cell membrane $\mathrm{e}^{38,43}$. As in other cell types ${ }^{36,38,46,50}$, sonoporation by an attached microbubble (Fig. 1B) also generated an influx of extracellular $\mathrm{Ca}^{2+}$ in hESCs (Fig. 1C,D), indicating that these phenomena are independent of cell types.

Dye transfer to neighboring cells after sonoporation-induced PI loading clearly revealed the functional GJIC in the cells (Fig. 2, Movie S1). For imaging GJIC in hESCs in a colony (Fig. 3), sonoporation was applied to enable rapid PI loading into multiple cells simultaneously (Fig. 3A), followed by dye transfer to neighboring cells (Movie S2, Fig. 3D).

Determination of cell-cell permeability between hESCs. Formation of a small (e.g. 10-30 nm) and transient pore (2-5 s) in sonoporation ${ }^{38,41,43}$ enabled a fixed amount of extracellular PI or $\mathrm{Ca}^{2+}$ to enter the cells. We assessed GJIC based on subsequent diffusion of these molecules to neighboring cells (Fig. 4A, Movie S3).

Under the condition described in Materials and Methods, we applied a 1D semi-infinite diffusion model to study the transport of PI from a sonoporated cell to an adjacent cell (Fig. 4A). Due to relatively faster processes of PI-nucleic acids binding and intracellular diffusion of PI molecules within the sonoporated cell compared to transport across GJs, we considered PI concentration in a sonoporated cell approximately constant for Eq. (8), which was confirmed in experiments that after a period of time after dye loading, the PI fluorescence intensity plateaued. Therefore we only used data after this time period for model fitting. For example, only data after $46.5 \mathrm{~s}$ in Fig. 4 were used.

PI fluorescence intensity in the nucleus is much stronger than that in the cytoplasm because of higher nucleic acids concentration in the nucleus. To avoid making assumptions of nucleic acid concentrations, we only used PI data in the cytoplasm for model fitting of Eq. (8) (Fig. 4B) and obtained GJ permeability $k=(0.156 \pm 0.033) \mu \mathrm{m} / \mathrm{s}$ 

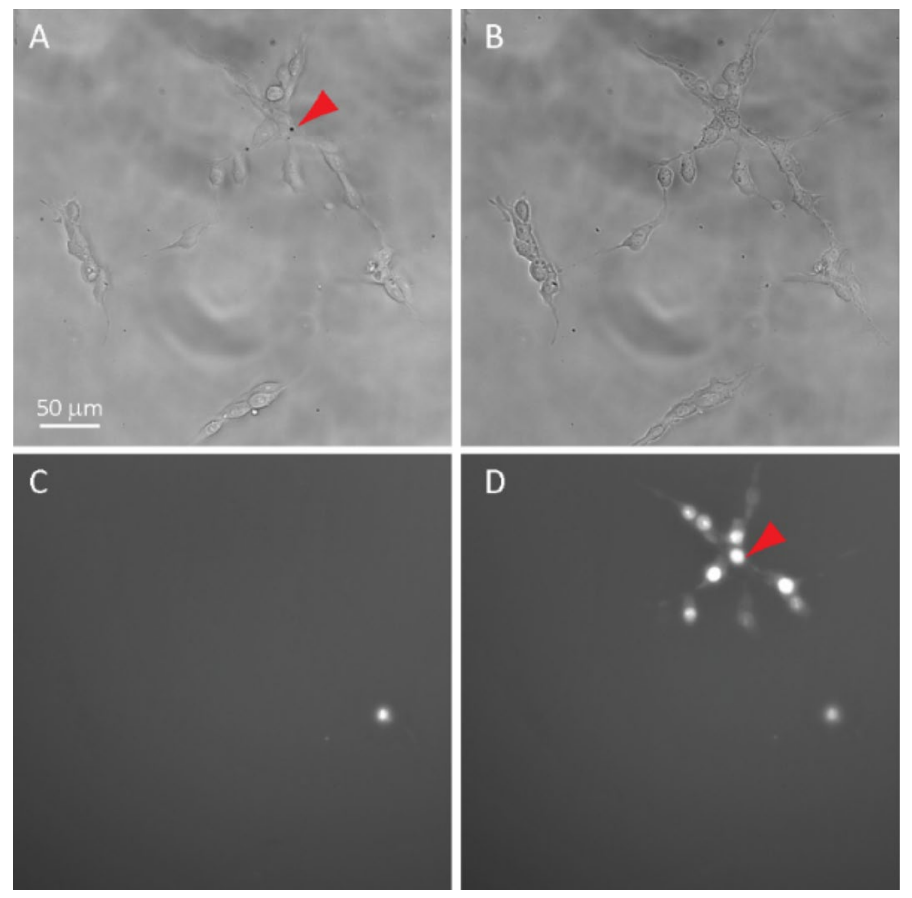

Figure 2. Single cell loading of propidium iodide (PI) by sonoporation and cell-cell dye transfer via gap junctions (GJs) in hESCs. (A) Bright field image of hESCs before sonoporation with a cell-attached microbubble (arrow). (B) Bright field image of hESCs after sonoporation. (C) PI fluorescent image before sonoporation. (D) PI fluorescent image of hESCs after sonoporation at steady state, showing the uptake of PI in the sonoporated cell (arrow) and the surrounding cells after cell-cell dye transfer via GJs.
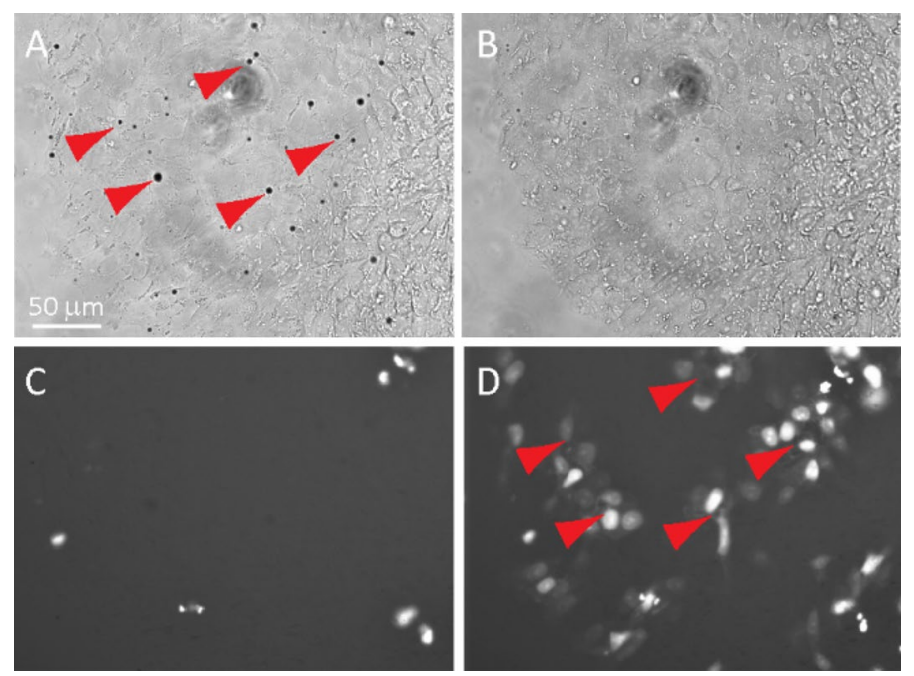

Figure 3. Dye (PI) loading into multiple single cells by sonoporation and cell-cell dye transfer via gap junctions (GJs) in a hESC colony. (A) Bright field image before sonoporation with microbubbles (arrows) attached to multiple cells. (B) Bright field image of hESCs after sonoporation. (C) Fluorescent image of PI before sonoporation. Dead cells show high PI intensity that were not related to sonoporation. (D) Fluorescent image showing intracellular uptake of PI in the cells with attached microbubbles in (A) (arrow) after sonoporation and surrounding cells due to subsequent cell-cell dye transfer via GJs.

$(n=9)$ and diffusion coefficient $D=(7.40 \pm 3.3) \times 10^{-9} \mathrm{~cm}^{2} / \mathrm{s}(n=9)$, which are consistent with reported values in other cells. For example, the previously reported unitary permeability of GJ channels to second messengers cAMP and $\mathrm{InsP}_{3}$ as well as LY for Hela cells ${ }^{51}$, when converted to cell-cell permeability, was $0.62 \mu \mathrm{m} / \mathrm{s}, 0.79 \mu \mathrm{m} / \mathrm{s}$, and $0.092 \mu \mathrm{m} / \mathrm{s}$, respectively, assuming a cell-cell contact area of $25 \mu \mathrm{m}^{2}$ and a number of $330 \mathrm{GJ}$ channels ${ }^{51}$. Our 
A
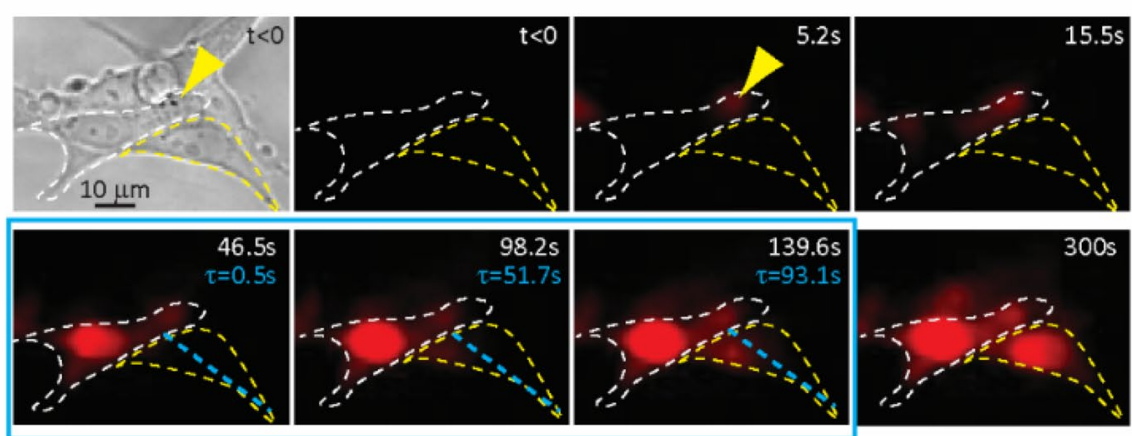

B
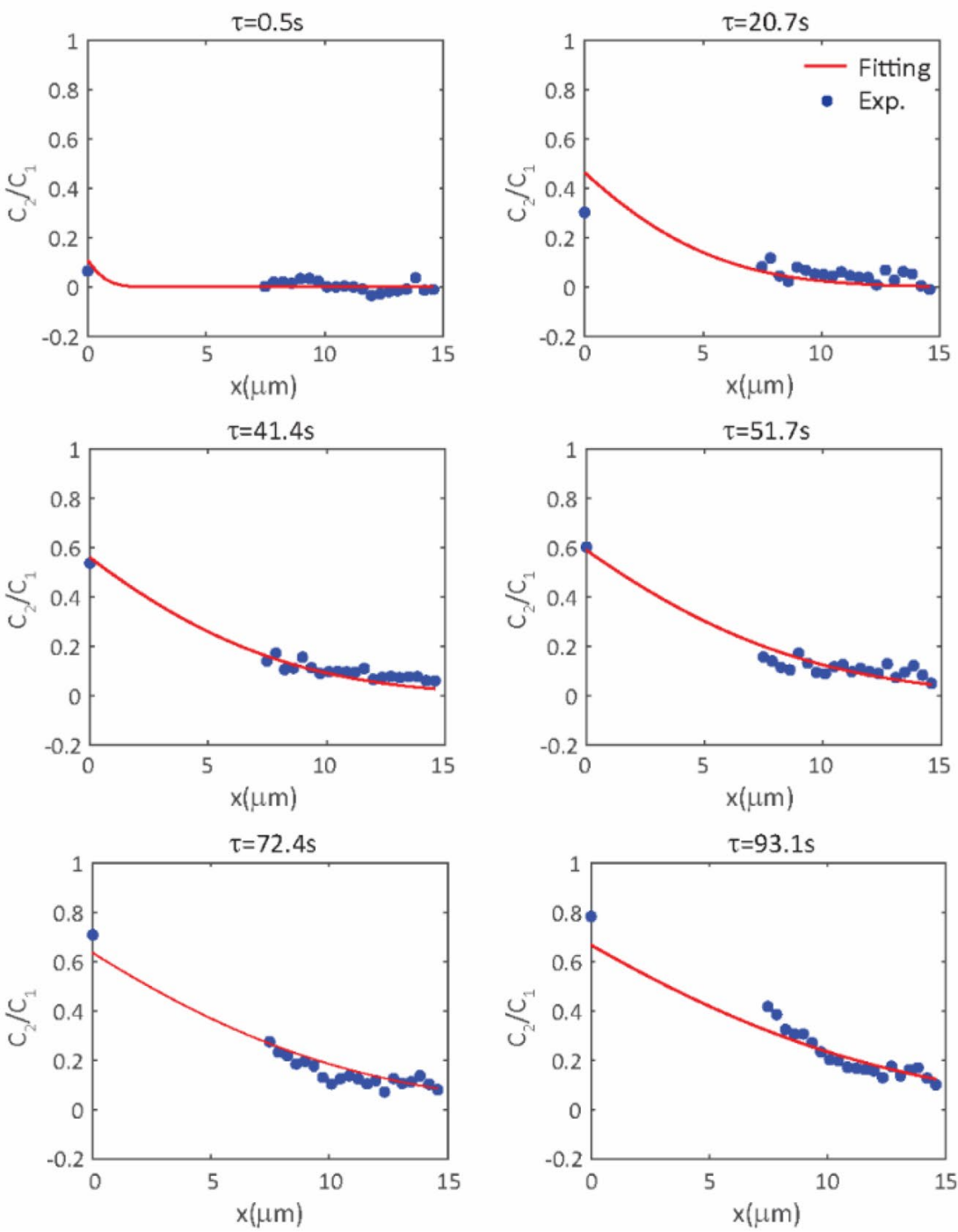

Figure 4. Determination of gap junction (GJ) permeability from cell-cell propidium iodide (PI) transfer and subsequent intracellular diffusion using an 1D semi-infinite medium diffusion model. (A) Sonoporation $(t=0)$ of a single cell (white dashed outline) via a membrane-bound microbubble (yellow arrow) permitted intracellular uptake of PI and PI transport into a neighboring cell (yellow dashed outline). Data from the blue highlighted frames represent steady state of PI in the sonoporated cell and were used for model fitting. Blue dashed line within the recipient cell indicates the 1D spatial distance from the GJ separating the sonoporated cell and recipient cell. (B) Plots of normalized PI concentration from model prediction and experimental data along the blue dash line within the recipient cell in (A) at different time points. Data points representing PI intensity within the nucleus of the recipient cell were not shown and not used in model fitting. Ultrasound pulse duration was $8 \mu$ s, acoustic pressure $0.4 \mathrm{MPa}$. 
A
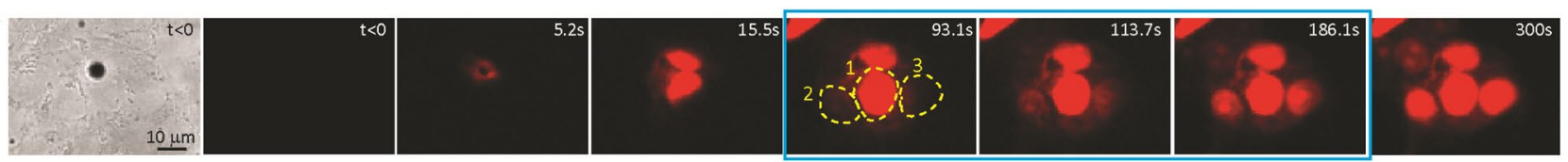

B

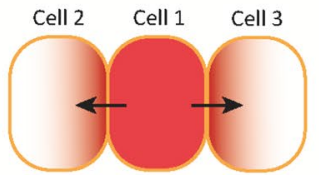

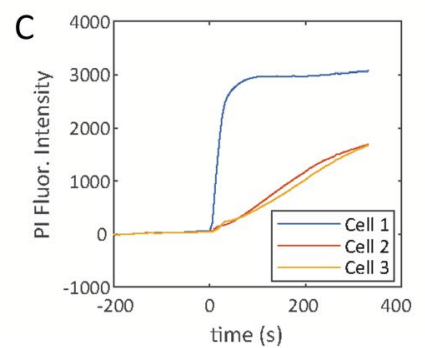
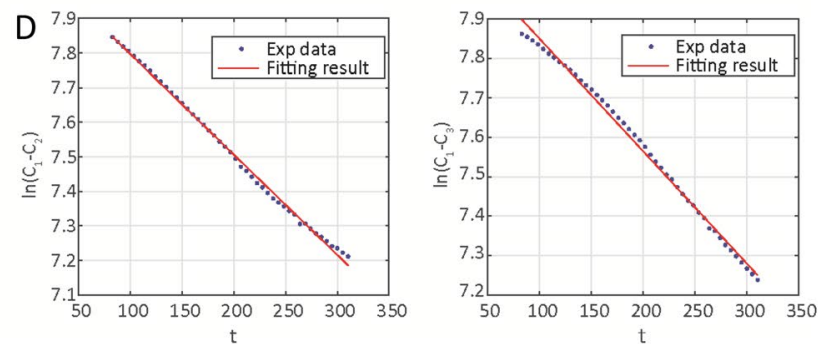

Figure 5. Estimation of gap junction (GJ) permeability using a quasi-steady state diffusion model. (A) Sequence of images show that microbubble mediated sonoporation induced influx of propidium iodide (PI) in a single cell (cell 1), followed by PI diffusion into two neighboring cells (cell 2 and cell 3 ). The three images within the blue frame were used for model fitting. Ultrasound pulse (duration $8 \mu \mathrm{s}, 0.4 \mathrm{MPa}$ ) was applied at $t=0$. (B) Schematic illustration of quasi-steady state diffusion from sonoporated cell (cell 1) to neighboring cells. (C) Measured PI fluorescence intensity over time in cell 1, 2, and 3 in (A). (D) Model fitting of measured PI intensities for GJ permeability estimation using data from cell 1, 2, and 3 in (A).

A
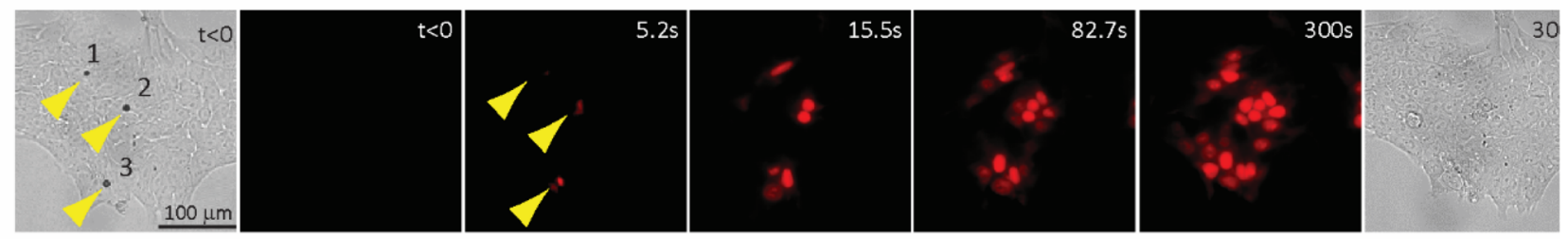

B

\begin{tabular}{l|l|l|l|l|l|l}
\hline $\begin{array}{l}\text { Permeability } \\
(\mu \mathrm{m} / \mathrm{s}), \mathrm{A}_{\mathrm{m}}=25 \mu \mathrm{m}^{2}\end{array}$ & & & & & & mean \pm std \\
\hline Location 1 & 0.227 & 0.351 & & & & $0.289 \pm 0.062$ \\
\hline Location 2 & 0.188 & 0.206 & 0.227 & 0.156 & 0.195 & $0.194 \pm 0.023$ \\
\hline Location 3 & 0.322 & 0.136 & & & & $0.229 \pm 0.093$ \\
\hline
\end{tabular}

Figure 6. Estimation of gap junction (GJ) permeability in multiple cells using a quasi-steady state diffusion model. (A) Sonoporation of multiple single cells facilitated by attached microbubbles (arrows in the first bright field image) in a hESC colony for PI loading, followed by dye transfer through GJs into neighboring cells. (B) Calculated values of GJ permeability for different GJs at the three locations marked in (A). The area of GJ was assume to be $25 \mu \mathrm{m}^{2}$.

results are also comparable with the GJ permeability reported for calcein ${ }^{52}, 0.088$ to $4.2 \mu \mathrm{m} / \mathrm{s}$, after conversion to cell-cell permeability, assuming a cell-cell contact area of $25 \mu \mathrm{m}^{2}$ and $110 \mathrm{GJ}$ channels ${ }^{52}$.

Measurement of cell-cell permeability in hESC colonies. As described in Materials and Methods, we also employed a lumped-parameter model of dye coupling between sonoporated cells and recipient cells to estimate GJ permeability. In this model, the total PI signal in a cell was considered without spatial dependence, and change of PI intensity vs. time was utilized to obtain cell-cell permeability.

As shown in Fig. 5 and illustrated by Eq. (14), we examined PI coupling after sonoporation (Fig. 5B, Movie S4) based on the total intracellular PI intensity in the whole cell over time. Satisfying the assumption for the diffusion model, we only used PI data after the intensity reached constant in the sonoporated cell (from 93.1-186.1 s, Fig. 5A,C) for fitting Eq. (14) (Fig. 5D), and obtained cell-cell permeability $k=(0.139 \pm 0.038) \mu \mathrm{m} / \mathrm{s}(n=20)$, a value comparable with the result obtained using the $1 \mathrm{D}$ semi-infinite medium diffusion model described in the previous section. Here we used a cell volume (as the product of cell area and a height of $5 \mu \mathrm{m}$ ) of $1150 \mu \mathrm{m}^{3}$ and functional GJ area of $25 \mu \mathrm{m}^{2}$ for our model. 
Heterogeneous distribution of GJIC in hESCs. Using the above lumped-parameter, compartment model of mass transport, we obtained the cell-cell permeability or the permeability of functional GJs of hESCs at multiple locations in the same colony (Fig. 6, Movie S5). Notably in these cases, a varying number of dye coupling events were detected surrounding different sonoporated cells (Fig. 6A, Movie S5), although the sonoporated (donor) cells were surrounded by other cells in a similar fashion in the colony. For example, PI transfers from a sonoporated cell to two adjacent cells (Fig. 6A) were detected at location 1, whereas PI transfer from a sonoporated donor cell to five adjacent recipient cells were detected at location 2, suggesting inhomogeneous distributions of functional GJs in hESCs, although the average GJ permeability values for the functional GJs between different pair of cells (Fig. 6B) were similar at different locations.

We conducted further experiments to assess the extent and progression of functional cell-cell communications in hESCs. Our results show that after 1 day of culture, there were $17.2 \pm 6.89 \%(n=3)$ of cells adjacent to sonoporated cells that exhibited detectable PI coupling from sonoporated cells (total of 39 sonoporated cells), suggesting the establishment of cell-cell communications in hESC colonies after 1 day of culture. The percentage of neighboring cells with PI coupling from a sonoporated cell increased after 4 day and 8 day of culture, to $30.8 \pm 9.57 \%$ ( $n=3$, total 41 sonoporated cells ) on day 4 and $32.6 \pm 6.42 \%$ ( $n=3$; total 35 sonoporated cells) on day 8 , respectively. However, the increases of PI coupling between cells in close range were not statistically significant.

We found that culture duration did not affect the permeability values of functional GJs surrounding a sonoporated cell (Fig. S1A). However, the spatial range of PI diffusion from sonoporated cells in terms of the number of cells exhibiting PI uptake increased with culture time (Fig. S1B). Specifically, the average number of successive cells with PI uptake associated with a sonoporated cell was $5.1 \pm 2.5$ cells $(n=35)$ on day 1 and increased to $6.14 \pm 3.1$ cells $(n=25)$ on day 4 and $8.4 \pm 4.0$ cells $(n=18)$ on day 8 , suggesting increased longer range cell-cell connectivity in a hESC colony over time.

Immunostaining of Connexin 43 in hESCs confirmed the protein expression in the cells, but did not show conclusive differences in expression pattern (Fig. S2) to correlate with the functional hererogeneity in GJIC observed in this study.

Sonoporation of single hESCs induced $\mathrm{Ca}^{2+}$ waves. With higher extracellular $\mathrm{Ca}^{2+}$ concentration than $\left[\mathrm{Ca}^{2+}\right]_{\mathrm{i}}$, influx of $\mathrm{Ca}^{2+}$ into the intracellular cytoplasm effectively increased $\left[\mathrm{Ca}^{2+}\right]_{\mathrm{i}}$ in the sonoporated cells (Fig. 1C). Interestingly, increases of $\left[\mathrm{Ca}^{2+}\right]_{\mathrm{i}}$ in other non-sonoporated hESCs in a colony were also observed after sonoporation (Fig. S2, Movie S6). The spatiotemporal changes of $\left[\mathrm{Ca}^{2+}\right]_{\mathrm{i}}$ in non-sonoporated hESCs exhibited a wave-like behavior, as intercellular calcium waves. Diffusion of intracellular $\mathrm{Ca}^{2+}$ through GJs likely played a role in the generation of intercellular calcium waves initiated from sonoporated cells.

To verify this, we conducted experiments using isolated hESCs without cell-cell contacts. Here sonoporation generated influx of $\mathrm{Ca}^{2+}$ into a single cell (Fig. 7A, Movie S7). Intracellular diffusion of $\mathrm{Ca}^{2+}$ within the cytosol, which sometimes is described as intracellular $\mathrm{Ca}^{2+}$ wave phenomelogically, resulted in a speed of $5.08 \pm 0.34 \mu \mathrm{m} / \mathrm{s}$ $(n=6)$ estimated from the increase of fluorescent signals within the cells (Fig. 7B). This value is consistent with the time scale of passive diffusion assuming a diffusion coefficient of $\mathrm{Ca}^{2+}$ in the cytosol ${ }^{53}$ at $5.3 \times 10^{-6} \mathrm{~cm}^{2} / \mathrm{s}$.

No changes in $\left[\mathrm{Ca}^{2+}\right]_{\mathrm{i}}$ were detected in other hESCs that were not in direct contact with the sonoporated cell (Fig. 7A,C, Movie S7), even when the cells were nearby (Fig. S3, Movie S8), suggesting that direct cell-cell contact and communication through GJs were required in intercellular $\mathrm{Ca}^{2+}$ waves in hESCs observed in this study.

Characteristics of intercellular $\mathrm{Ca}^{2+}$ waves and $\mathrm{Ca}^{2+}$ signaling in hESCs. Increases of $\left[\mathrm{Ca}^{2+}\right]_{\mathrm{i}}$ in hESCs can also come from other sources. For example, $\mathrm{Ca}^{2+}$-induced $\mathrm{Ca}^{2+}$ release from internal stores and calcium signaling ${ }^{54}$ can result in increase of $\left[\mathrm{Ca}^{2+}\right]_{i}$ patterns different from simple diffusion patterns. Indeed, we observed a variety of intercellular calcium wave patterns in this study.

In the example shown in Fig. 8 and Movie S9, intercellular $\mathrm{Ca}^{2+}$ wave exhibited complex spatiotemporal pattern. As shown in experiments, dye loading and initial increase of $\left[\mathrm{Ca}^{2+}\right]_{\mathrm{i}}$ only occurred in cells with attached microbubbles, no $\mathrm{Ca}^{2+}$ waves were generated in experiments with ultrasound but without microbubbles or with microbubbles but without ultrasound. Besides rapid increase of $\left[\mathrm{Ca}^{2+}\right]_{\mathrm{i}}$ in a sonoporated cell (cell 1) (Fig. 8A), spatial discontinuity and non-linear path were observed in the $\mathrm{Ca}^{2+}$ wave. The temporal change of $\left[\mathrm{Ca}^{2+}\right]_{\mathrm{i}}$ in hESCs did not correlate with their spatial locations relative to the sonoporated cell (cell 1). Cell 7 and cell 8 were situated closer to the sonoporated cell (cell 1) than cell 4 and cell 5; however, they exhibited an increase of $\left[\mathrm{Ca}^{2+}\right]_{\mathrm{i}}$ later than cell 4 and cell 5 (Fig. 8B,C). It is also clear from the image that not all hESCs surrounding the sonoporated cell (cell 1) exhibited changes in $\left[\mathrm{Ca}^{2+}\right]_{\mathrm{i}}$ following the increase of $\left[\mathrm{Ca}^{2+}\right]_{\mathrm{i}}$ in cell 1 (Fig. $8 \mathrm{~B}$ ). The observed discontinued $\mathrm{Ca}^{2+}$ wave pattern cannot be explained by diffusion of extracellular signaling molecules, as such diffusion would likely not be restricted to discrete cells within the colony. However, $\mathrm{Ca}^{2+}$ wave can be triggered by intercellular diffusion of other signaling molecules that were not imaged and the complex $\mathrm{Ca}^{2+}$ wave propagation pattern eflects the heterogeneous cell-cell connection network.

In addition, $\left[\mathrm{Ca}^{2+}\right]_{\mathrm{i}}$ exhibited different characteristics in both initiation time and temporal profile in different cells (Fig. 8C). Furthermore, the speed of calcium wave exhibited different values from cell to cell (Fig. 8D), suggesting variation in GJ permeability in the colony. Besides calcium signaling in hESCs, these complex $\left[\mathrm{Ca}^{2+}\right]_{\mathrm{i}}$ wave patterns may also be indicative of non-uniform distribution of functional GJs, made visible by $\mathrm{Ca}^{2+}$ activities initiated from single cells.

Both radially symmetric (Fig. 9A, Movie S10) and asymmetric $\mathrm{Ca}^{2+}$ waves (Fig. 9B, Movie S11) were observed. Symmetric calcium waves exhibited a wave speed $(4.31 \pm 1.55 \mu \mathrm{m} / \mathrm{s} ; n=36)$ greater than asymmetric waves $(2.56 \pm 1.03 \mu \mathrm{m} / \mathrm{s}$ in the fastest direction and $2.01 \pm 0.72 \mu \mathrm{m} / \mathrm{s}$ in the orthogonal direction; $n=8)$ (Fig. 9C). While a range of calcium wave speed values were detected for hESCs, calcium wave speed was not correlated with the values of $\left[\mathrm{Ca}^{2+}\right]_{\mathrm{i}}$ in sonoporated cells (Fig. 9D), suggesting that calcium wave speed was an intrinsic property of 
A
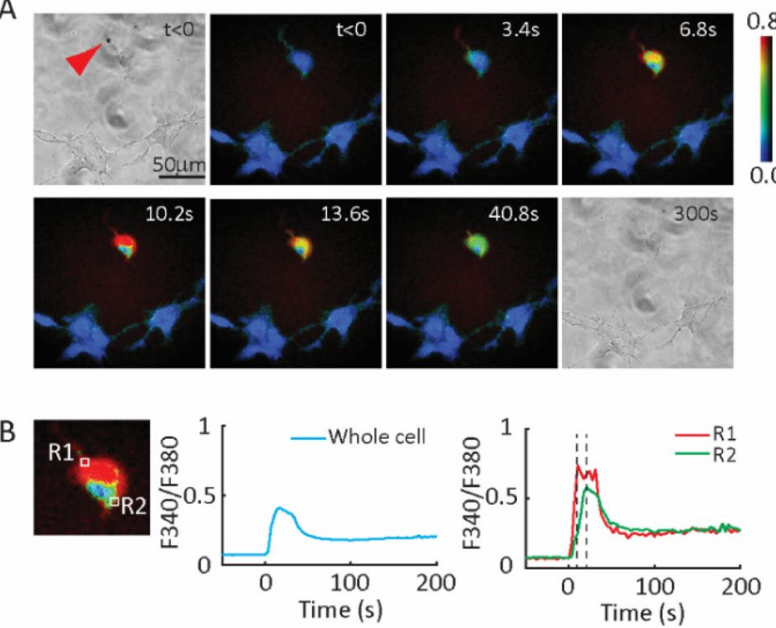

C

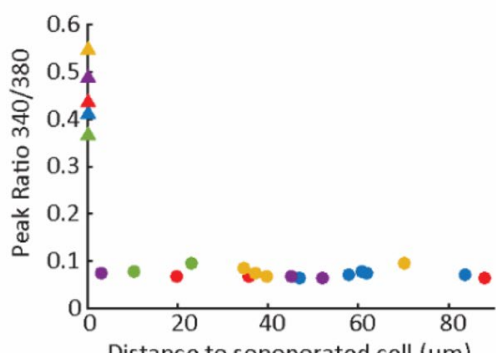

Figure 7. Intercellular $\mathrm{Ca}^{2+}$ waves in hESCs required cell-cell contact. (A) Sequence of images showing that cavitation of a microbubble (arrow) by a short ultrasound pulse $\left(8 \mu \mathrm{s}, 0.4 \mathrm{MPa}\right.$ ) induced $\mathrm{Ca}^{2+}$ influx into the cell. (B) Zoomed-in image of the sonoporated hESC in (A) with selected intracellular regions (R1 and R2). The plots show Fura2 fluorescence ratio $(340 \mathrm{~nm} / 380 \mathrm{~nm})$ over time for the whole cell, as well as R1 and R2. Time delay between R1 and R2 represented intracellular $\mathrm{Ca}^{2+}$ diffusion within the sonoporated cell. (C) Scatter plot of experimental data showing peak Fura2 fluorescence ratio $(340 \mathrm{~nm} / 380 \mathrm{~nm}$ ) in sonoporated hESCs (colored triangles) and the corresponding neighboring hESCs (colored circles) located at different distances. Triangle and circles with the same color indicate measurements from the same field of view in one experiment.

hESCs independent of the amount of $\mathrm{Ca}^{2+}$ influx due to sonoporation. The temporal characteristics of $\left[\mathrm{Ca}^{2+}\right]_{\mathrm{i}}$ were also different for cells in symmetric and asymmetric waves (Fig. 9E,F). Calcium oscillation was also observed (Fig. 9F, Movie S11), again indicating calcium signaling beyond simple $\mathrm{Ca}^{2+}$ diffusion.

\section{Discussion}

Direct molecular transport between cells through GJs has been well-documented as the mechanism for molecular exchange between adjacent cells. Recently, tunneling nanotubes (TNTs) have been discovered as a new route of direct cell-to-cell communication ${ }^{55-57}$. TNTs, formed as thin membrane channels between mammalian cells ${ }^{55-57}$, have been observed to facilitate long-range communication between dislodged cells. Found in a number of cell types and particularly in infected cells, there existence in hESCs are unknown. In this study, our results clearly show the robust cell-cell transport occurring exclusively in the cells that were in contact with the sonoporated cells. Therefore in this study, we regard the observed cell-cell molecular coupling as the result of transport through GJs in hESCs.

Our results demonstrate the feasibility of using sonoporation as a unique and advantageous strategy for dye loading into single live cells, compared to studies on GJ transport using conventional methods including scrape loading and microinjection. Our technique enables rapid dye loading into multiple single cells simultaneously, allowing assessment of GJ permeability at multiple sites with higher throughput, compared to single cell technique such as microinjection, and with single cell resolution, compared to techniques such as scrape loading.

We assumed the molecular transport from the sonoporated cell to an adjacent cell and diffusion as a 1D model. Considering the substantial contact area between the connected cells, this model is an approximation under the conditions described in the method section if the diffusion within a time limit is considered. Under this assumption, a close form solution is mathematically obtained so that experimental data are fitted to the model to obtain cell-cell permeability. Theoretically, the diffusion problem can be solved based on the mass transport equation with actual cell shapes and dimension without the 1D assumption. However, general treatment like this can only yield numerical solutions which do not provide the benefit of explicit relations of permeability in terms of the spatiotemporal dye concentration distribution. 
A

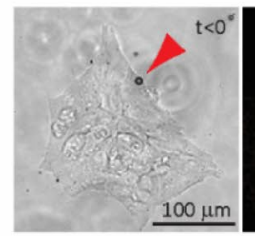

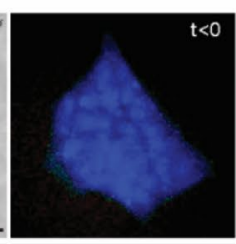
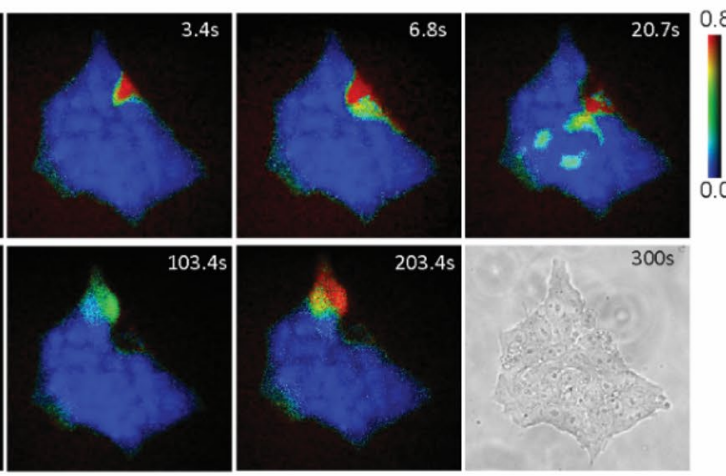

C
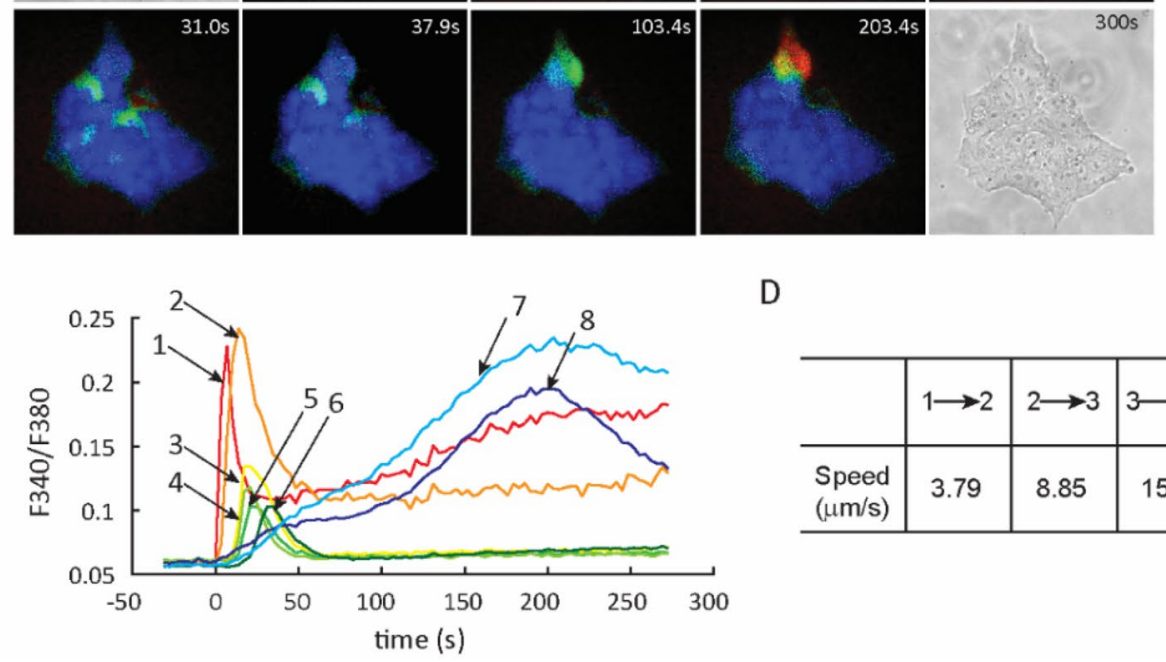

D
B

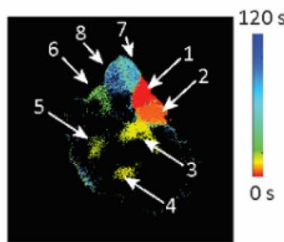

\begin{tabular}{l|l|l|l|l|l|l|l}
\hline & $1 \rightarrow 2$ & $2 \rightarrow 3$ & $3 \longrightarrow 4$ & $4 \longrightarrow 5$ & $5 \longrightarrow 6$ & $6 \rightarrow 7$ & $7 \rightarrow 8$ \\
\hline $\begin{array}{c}\text { Speed } \\
(\mu \mathrm{m} / \mathrm{s})\end{array}$ & 3.79 & 8.85 & 15.35 & 13.28 & 9.15 & 0.27 & 0.15 \\
\hline
\end{tabular}

Figure 8. Single cell sonoporation enabled visualization of intercellular calcium wave in a hESC colony with high spatiotemporal resolution. (A) Sequential images show that facilitated by a microbubble (red arrow), a single ultrasound pulse $(8 \mu \mathrm{s}, 0.4 \mathrm{MPa})$ induced $\mathrm{Ca}^{2+}$ influx in sonoporated cell (cell 1), initiating intercellular $\mathrm{Ca}^{2+}$ wave that propagated to cell 2 to 8 in a discontinuous fashion. (B) Heat map showing the time sequence of intracellular $\mathrm{Ca}^{2+}$ concentration increase in cell 1-8, indicating the $\mathrm{Ca}^{2+}$ wave propagated in a circle. (C) Plot of Fura2 fluorescence ratio $(340 \mathrm{~nm} / 380 \mathrm{~nm})$ showing the delay of increase in $\mathrm{Ca}^{2+}$ concentration for cell 1-8. (D) Cell-cell $\mathrm{Ca}^{2+}$ wave speed.

Our results show heterogeneous intercellular connectivity and $\mathrm{Ca}^{2+}$ wave characteristics in hESC colonies. Further studies are needed to examine the implication of these findings. For example, connexin expression in human pluripotent stem cells (hPSCs) has been found to be dramatically different between the pluripotent "naïve state" and the "primed state" ${ }^{\text {. }}$. Sonoporation may provide a tool to determine whether the changes in GJIC can serve as a functional biomarker for the pluripotency continuum in stem cells. The technique can also be used for investigating GJIC and $\mathrm{Ca}^{2+}$ in hPSCs to determine alteration of GJIC as the result of pathology or pharmacological and genetic intervention.

Similar to conventional studies of GJIC, we used fluorescent tracers to visualize molecule transport between cells. The use of PI enabled uninterrupted, continuous imaging of dynamic intercellular dye coupling without the need to wash after dye loading. Our estimation of GJ permeability relies on assumptions of cell volumes and areas separating two adjacent cells from microscopic images, although these factors do not impact assessment of overall cell-cell communication. Sonoporation should also work for other dye molecules, and it may be worth to further examine whether different dye molecules resulted in different GJ transport patterns.

Unlike conventional methods that use chemical agents to invoke calcium activities in a population of cells without spatial distinction, microbubble-facilitated sonoporation initiates $\mathrm{Ca}^{2+}$ activities from single hESCs, a capability particularly useful for investigating GJIC networks and $\mathrm{Ca}^{2+}$ signaling with high spatiotemporal resolution. As a universal carrier of biological signals $s^{54}, \mathrm{Ca}^{2+}$ controls numerous cell functions, including cell proliferation and apoptosis ${ }^{59}$. $\mathrm{Ca}^{2+}$ signaling is critical for proliferation and directed differentiation of $\mathrm{hESCs}^{60,61}$, although details of $\mathrm{Ca}^{2+}$ signaling and regulation of intracellular $\mathrm{Ca}^{2+}$ concentration $\left(\left[\mathrm{Ca}^{2+}\right]_{\mathrm{i}}\right)$ in hESCs are incompletely understood ${ }^{44,45}$. Information of the amplitude, range, and heterogeneity of GJIC in hESCs could be useful for experimental investigation and mathematical modeling of hESC behaviors. 
A

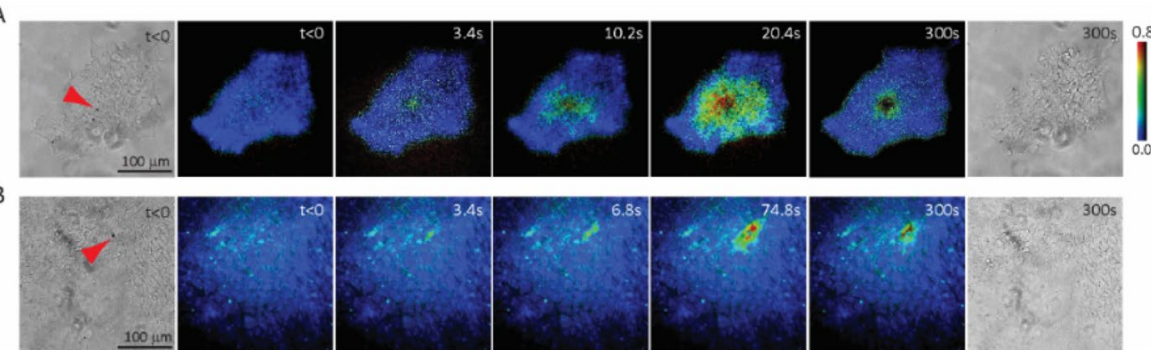

C
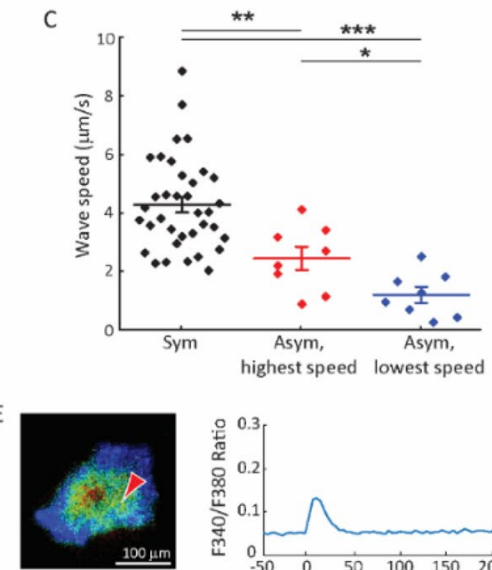
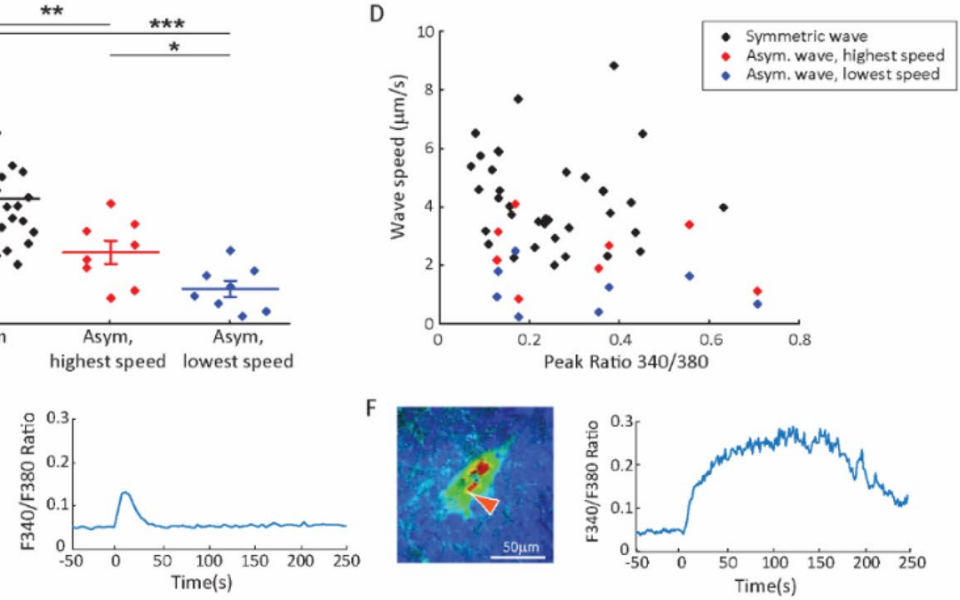

Figure 9. Symmetric and asymmetric intercellular $\mathrm{Ca}^{2+}$ waves in hESCs induced by single cell sonoporation. (A) A symmetric $\mathrm{Ca}^{2+}$ wave initiated from a single cell by sonoporation via a microbubble (arrow). (B) An asymmetric $\mathrm{Ca}^{2+}$ wave initiated from a single cell by sonoporation via a microbubble (arrow). (C) Wave speed for symmetric waves $(4.31 \pm 1.55 \mu \mathrm{m} / \mathrm{s} ; n=36)$, as well as the fastest speed $(2.56 \pm 1.03 \mu \mathrm{m} / \mathrm{s} ; n=8)$ and slowest speed $(1.22 \pm 0.72 \mu \mathrm{m} / \mathrm{s} ; n=8)$ for asymmetric waves. (D) Scatter plot of wave speed and peak Fura2 fluorescence ratio $(340 \mathrm{~nm} / 380 \mathrm{~nm})$ in sonoporated cells. (E) Fura2 fluorescence intensity ratio in a single cell (arrow) in (A) after sonoporation showing increase and recovery of intracellular $\mathrm{Ca}^{2+}$ concentration. (F) Fura2 fluorescence intensity ratio in a cell (arrow) in (B) showing increase and decrease as well as $\mathrm{Ca}^{2+}$ concentration oscillation (at $170-200 \mathrm{~s}$ ) after single cell sonoporation. Ultrasound pulse duration was $8 \mu \mathrm{s}$ with an acoustic pressure of $0.4 \mathrm{MPa}$.

Although this study used hESCs to demonstrate the feasibility of sonoporation for studying GJIC and $\mathrm{Ca}^{2+}$ signaling, our technique is readily applicable to other cell types for quantifying GJIC as a functional biomarker for assessing disease progression, adverse effects of toxicants ${ }^{4}$, chemical carcinogenesis ${ }^{62}$, and efficacy of drugs ${ }^{29}$.

Received: 23 April 2020; Accepted: 8 October 2020

Published online: 26 October 2020

\section{References}

1. Loewenstein, W. R., Socolar, S. J., Higashino, S., Kanno, Y. \& Davidson, N. Intercellular communication: renal, urinary bladder, sensory, and salivary gland cells. Science 149, 295-298. https://doi.org/10.1126/science.149.3681.295 (1965).

2. Aasen, T., Mesnil, M., Naus, C. C., Lampe, P. D. \& Laird, D. W. Gap junctions and cancer: communicating for 50 years. Nat. Rev. Cancer 16, 775-788. https://doi.org/10.1038/nrc.2016.105 (2016).

3. Loewenstein, W. R. \& Kanno, Y. Intercellular communication and the control of tissue growth: lack of communication between cancer cells. Nature 209, 1248-1249. https://doi.org/10.1038/2091248a0 (1966).

4. Trosko, J. E. \& Chang, C. C. Role of stem cells and gap junctional intercellular communication in human carcinogenesis. Radiat. Res. 155, 175-180 (2001).

5. Trosko, J. E. The role of stem cells and gap junctional intercellular communication in carcinogenesis. J. Biochem. Mol. Biol. 36, 43-48 (2003).

6. Trosko, J. E. et al. Gap junctions and the regulation of cellular functions of stem cells during development and differentiation. Methods 20, 245-264. https://doi.org/10.1006/meth.1999.0941 (2000).

7. Worsdorfer, P., Wagner, N. \& Ergun, S. The role of connexins during early embryonic development: pluripotent stem cells, gene editing, and artificial embryonic tissues as tools to close the knowledge gap. Histochem. Cell Biol. 150, 327-339. https://doi.org/ 10.1007/s00418-018-1697-2 (2018).

8. Thomson, J. A. et al. Embryonic stem cell lines derived from human blastocysts. Science 282, 1145-1147 (1998).

9. Etoc, F. et al. A balance between secreted inhibitors and edge sensing controls gastruloid self-organization. Dev. Cell 39, 302-315. https://doi.org/10.1016/j.devcel.2016.09.016 (2016).

10. Warmflash, A., Sorre, B., Etoc, F., Siggia, E. D. \& Brivanlou, A. H. A method to recapitulate early embryonic spatial patterning in human embryonic stem cells. Nat. Methods 11, 847-854. https://doi.org/10.1038/nmeth.3016 (2014). 
11. Shao, Y. et al. Self-organized amniogenesis by human pluripotent stem cells in a biomimetic implantation-like niche. Nat. Mater. 16, 419-425. https://doi.org/10.1038/nmat4829 (2017).

12. Shao, Y. et al. A pluripotent stem cell-based model for post-implantation human amniotic sac development. Nat. Commun. 8, 208. https://doi.org/10.1038/s41467-017-00236-w (2017).

13. Beccari, L. et al. Multi-axial self-organization properties of mouse embryonic stem cells into gastruloids. Nature 562, 272-276. https://doi.org/10.1038/s41586-018-0578-0 (2018).

14. Xue, X. et al. Mechanics-guided embryonic patterning of neuroectoderm tissue from human pluripotent stem cells. Nat. Mater. 17, 633-641 (2018).

15. Simunovic, M. et al. A 3D model of a human epiblast reveals BMP4-driven symmetry breaking. Nat. Cell Biol. 21, 900-910. https:// doi.org/10.1038/s41556-019-0349-7 (2019).

16. Zheng, Y. et al. Controlled modelling of human epiblast and amnion development using stem cells. Nature 573, 421-425. https:// doi.org/10.1038/s41586-019-1535-2 (2019).

17. Odorico, J. S., Kaufman, D. S. \& Thomson, J. A. Multilineage differentiation from human embryonic stem cell lines. Stem Cells 19, 193-204. https://doi.org/10.1634/stemcells.19-3-193 (2001).

18. Bauwens, C. L. et al. Control of human embryonic stem cell colony and aggregate size heterogeneity influences differentiation trajectories. Stem Cells 26, 2300-2310. https://doi.org/10.1634/stemcells.2008-0183 (2008).

19. Nemashkalo, A., Ruzo, A., Heemskerk, I. \& Warmflash, A. Morphogen and community effects determine cell fates in response to BMP4 signaling in human embryonic stem cells. Development 144, 3042-3053. https://doi.org/10.1242/dev.153239 (2017).

20. Rosowski, K. A., Mertz, A. F., Norcross, S., Dufresne, E. R. \& Horsley, V. Edges of human embryonic stem cell colonies display distinct mechanical properties and differentiation potential. Sci. Rep. 5, 14218. https://doi.org/10.1038/srep14218 (2015).

21. Topal, T. et al. Acoustic tweezing cytometry induces rapid initiation of human embryonic stem cell differentiation. Sci. Rep. 8, 12977. https://doi.org/10.1038/s41598-018-30939-z (2018).

22. Glen, C. M., McDevitt, T. C. \& Kemp, M. L. Dynamic intercellular transport modulates the spatial patterning of differentiation during early neural commitment. Nat. Commun. 9, 4111. https://doi.org/10.1038/s41467-018-06693-1 (2018).

23. Li, L. et al. Individual cell movement, asymmetric colony expansion, rho-associated kinase, and E-cadherin impact the clonogenicity of human embryonic stem cells. Biophys. J. 98, 2442-2451. https://doi.org/10.1016/j.bpj.2010.02.029 (2010).

24. Huettner, J. E. et al. Gap junctions and connexon hemichannels in human embryonic stem cells. Stem Cells 24, 1654-1667. https:// doi.org/10.1634/stemcells.2005-0003 (2006).

25. Wong, R. C., Pebay, A., Nguyen, L. T., Koh, K. L. \& Pera, M. F. Presence of functional gap junctions in human embryonic stem cells. Stem Cells 22, 883-889. https://doi.org/10.1634/stemcells.22-6-883 (2004).

26. Wong, R. C. et al. Gap junctions modulate apoptosis and colony growth of human embryonic stem cells maintained in a serumfree system. Biochem. Biophys. Res. Commun. 344, 181-188. https://doi.org/10.1016/j.bbrc.2006.03.127 (2006).

27. Pebay, A. \& Wong, R. C. Study of gap junctions in human embryonic stem cells. Methods Mol. Biol. 1307, 105-121. https://doi. org/10.1007/7651_2014_83(2016).

28. Abbaci, M., Barberi-Heyob, M., Blondel, W., Guillemin, F. \& Didelon, J. Advantages and limitations of commonly used methods to assay the molecular permeability of gap junctional intercellular communication. Biotechniques 45(33-52), 56-62. https://doi. org/10.2144/000112810 (2008).

29. Babica, P., Sovadinova, I. \& Upham, B. L. Scrape loading/dye transfer assay. Methods Mol. Biol. 1437, 133-144. https://doi.org/10. 1007/978-1-4939-3664-9_9 (2016).

30. Saez, J. C., Connor, J. A., Spray, D. C. \& Bennett, M. V. Hepatocyte gap junctions are permeable to the second messenger, inositol 1,4,5-trisphosphate, and to calcium ions. Proc. Natl. Acad. Sci. USA 86, 2708-2712. https://doi.org/10.1073/pnas.86.8.2708 (1989).

31. Fridman, M. D., Liu, J., Sun, Y. \& Hamilton, R. M. Microinjection technique for assessment of gap junction function. Methods Mol. Biol. 1437, 145-154. https://doi.org/10.1007/978-1-4939-3664-9_10 (2016).

32. Neyton, J. \& Trautmann, A. Single-channel currents of an intercellular junction. Nature 317, 331-335. https://doi.org/10.1038/ 317331a0 (1985).

33. Van Rijen, H. V., Wilders, R., Rook, M. B. \& Jongsma, H. J. Dual patch clamp. Methods Mol. Biol. 154, 269-292. https://doi.org/ 10.1385/1-59259-043-8:269 (2001).

34. Decrock, E. et al. Electroporation loading and dye transfer: a safe and robust method to probe gap junctional coupling. Methods Mol. Biol. 1437, 155-169. https://doi.org/10.1007/978-1-4939-3664-9_11 (2016).

35. Ferrara, K., Pollard, R. \& Borden, M. Ultrasound microbubble contrast agents: fundamentals and application to gene and drug delivery. Annu. Rev. Biomed. Eng. 9, 415-447. https://doi.org/10.1146/annurev.bioeng.8.061505.095852 (2007).

36. Fan, Z., Kumon, R. E., Park, J. \& Deng, C. X. Intracellular delivery and calcium transients generated in sonoporation facilitated by microbubbles. J. Control Release 142, 31-39. https://doi.org/10.1016/j.jconrel.2009.09.031 (2010).

37. Fan, Z., Chen, D. \& Deng, C. X. Improving ultrasound gene transfection efficiency by controlling ultrasound excitation of microbubbles. J. Control Release 170, 401-413. https://doi.org/10.1016/j.jconrel.2013.05.039 (2013).

38. Fan, Z., Liu, H., Mayer, M. \& Deng, C. X. Spatiotemporally controlled single cell sonoporation. Proc. Natl. Acad. Sci. USA 109, 16486-16491. https://doi.org/10.1073/pnas.1208198109 (2012).

39. Deng, C. X. \& Lizzi, F. L. A review of physical phenomena associated with ultrasonic contrast agents and illustrative clinical applications. Ultrasound Med. Biol. 28, 277-286 (2002).

40. Fan, Z., Chen, D. \& Deng, C. X. Characterization of the dynamic activities of a population of microbubbles driven by pulsed ultrasound exposure in sonoporation. Ultrasound Med. Biol. 40, 1260-1272. https://doi.org/10.1016/j.ultrasmedbio.2013.12.002 (2014).

41. Deng, C. X., Sieling, F., Pan, H. \& Cui, J. Ultrasound-induced cell membrane porosity. Ultrasound Med. Biol. 30, 519-526. https:// doi.org/10.1016/j.ultrasmedbio.2004.01.005 (2004).

42. Fan, Z., Kumon, R. E. \& Deng, C. X. Mechanisms of microbubble-facilitated sonoporation for drug and gene delivery. Ther. Deliv. 5, 467-486. https://doi.org/10.4155/tde.14.10 (2014).

43. Zhou, Y., Kumon, R. E., Cui, J. \& Deng, C. X. The size of sonoporation pores on the cell membrane. Ultrasound Med. Biol. 35, 1756-1760. https://doi.org/10.1016/j.ultrasmedbio.2009.05.012 (2009).

44. Apati, A., Berecz, T. \& Sarkadi, B. Calcium signaling in human pluripotent stem cells. Cell Calcium 59, 117-123. https://doi.org/ 10.1016/j.ceca.2016.01.005 (2016).

45. Pentek, A., Paszty, K. \& Apati, A. Analysis of intracellular calcium signaling in human embryonic stem cells. Methods Mol. Biol. 1307, 141-147. https://doi.org/10.1007/7651_2014_68 (2016).

46. Kumon, R. E. et al. Spatiotemporal effects of sonoporation measured by real-time calcium imaging. Ultrasound Med. Biol. 35 , 494-506. https://doi.org/10.1016/j.ultrasmedbio.2008.09.003 (2009).

47. Kumon, R. E. et al. Ultrasound-induced calcium oscillations and waves in Chinese hamster ovary cells in the presence of microbubbles. Biophys. J. 93, L29-31. https://doi.org/10.1529/biophysj.107.113365 (2007).

48. Truskey, G. A., Yuan, F. \& Katz, D. F. Transport Phenomena in Biological Systems 2nd edn. (Pearson Prentice Hall, Upper Saddle River, 2009).

49. Crank, J. The Mathematics of Diffusion $2 d$ edn. (Oxford University Press, Oxford, 1979).

50. Zhou, Y., Cui, J. \& Deng, C. X. Dynamics of sonoporation correlated with acoustic cavitation activities. Biophys. J. 94, L51-53. https://doi.org/10.1529/biophysj.107.125617 (2008). 
51. Hernandez, V. H. et al. Unitary permeability of gap junction channels to second messengers measured by FRET microscopy. Nat. Methods 4, 353-358. https://doi.org/10.1038/nmeth1031 (2007).

52. Eckert, R. Gap-junctional single-channel permeability for fluorescent tracers in mammalian cell cultures. Biophys. J. 91, 565-579. https://doi.org/10.1529/biophysj.105.072306 (2006).

53. Donahue, B. S. \& Abercrombie, R. F. Free diffusion coefficient of ionic calcium in cytoplasm. Cell Calcium 8, 437-448 (1987).

54. Berridge, M. J., Bootman, M. D. \& Roderick, H. L. Calcium signalling: dynamics, homeostasis and remodelling. Nat. Rev. Mol. Cell. Biol. 4, 517-529. https://doi.org/10.1038/nrm1155 (2003).

55. Gerdes, H. H., Bukoreshtliev, N. V. \& Barroso, J. F. Tunneling nanotubes: a new route for the exchange of components between animal cells. FEBS Lett. 581, 2194-2201. https://doi.org/10.1016/j.febslet.2007.03.071 (2007).

56. Ariazi, J. et al. Tunneling nanotubes and gap junctions-their role in long-range intercellular communication during development, health, and disease conditions. Front. Mol. Neurosci. 10, 333. https://doi.org/10.3389/fnmol.2017.00333 (2017).

57. Drab, M., Stopar, D., Kralj-Iglic, V. \& Iglic, A. Inception mechanisms of tunneling nanotubes. Cells https://doi.org/10.3390/cells 8060626 (2019).

58. Esseltine, J. L. et al. Dynamic regulation of connexins in stem cell pluripotency. Stem Cells 38, 52-66. https://doi.org/10.1002/stem. $3092(2020)$.

59. Orrenius, S., Zhivotovsky, B. \& Nicotera, P. Regulation of cell death: the calcium-apoptosis link. Nat. Rev. Mol. Cell. Biol. 4, 552-565. https://doi.org/10.1038/nrm1150 (2003).

60. Ermakov, A. et al. A role for intracellular calcium downstream of G-protein signaling in undifferentiated human embryonic stem cell culture. Stem Cell Res. 9, 171-184. https://doi.org/10.1016/j.scr.2012.06.007 (2012).

61. Toth, A. B., Shum, A. K. \& Prakriya, M. Regulation of neurogenesis by calcium signaling. Cell Calcium 59, 124-134. https://doi. org/10.1016/j.ceca.2016.02.011 (2016).

62. Yamasaki, H. Changes of gap junctional intercellular communication during multistage carcinogenesis. Prog. Clin. Biol. Res. 340D, 153-164 (1990).

\section{Acknowledgements}

This work is supported by the National Institutes of Health (R01 EB019436 to CXD and JF).

\section{Author contributions}

Z.F. performed sonoporation experiments and associated data analyses as well as contributed to writing of the manuscript. X.X. participated in experiments in terms of sample preparation and assays. J.F. and C.X.D. directed the study, led project design and data interpretation, and wrote the manuscript. All authors have approved the manuscript.

\section{Competing interests}

The authors declare no competing interests.

\section{Additional information}

Supplementary information is available for this paper at https://doi.org/10.1038/s41598-020-75347-4.

Correspondence and requests for materials should be addressed to C.X.D.

Reprints and permissions information is available at www.nature.com/reprints.

Publisher's note Springer Nature remains neutral with regard to jurisdictional claims in published maps and institutional affiliations.

(c) (i) Open Access This article is licensed under a Creative Commons Attribution 4.0 International License, which permits use, sharing, adaptation, distribution and reproduction in any medium or format, as long as you give appropriate credit to the original author(s) and the source, provide a link to the Creative Commons licence, and indicate if changes were made. The images or other third party material in this article are included in the article's Creative Commons licence, unless indicated otherwise in a credit line to the material. If material is not included in the article's Creative Commons licence and your intended use is not permitted by statutory regulation or exceeds the permitted use, you will need to obtain permission directly from the copyright holder. To view a copy of this licence, visit http://creativecommons.org/licenses/by/4.0/.

(C) The Author(s) 2020 